\title{
SISTEM PENDUKUNG KEPUTUSAN PENENTUAN JURUSAN DENGAN METODE ANALYTHICAL HIERARCHY PROCESS ( STUDI KASUS : SMK GANESHA LAMPUNG TIMUR )
}

\author{
Guna Yanti kemala Sari Siregar Pahü ${ }^{\# 1}$, Pujianto ${ }^{* 2}$, Lilik Joko Susanto ${ }^{\# 3}$ \\ Jurusan Ilmu Komputer \\ Universitas Muhammadiyah Metro \\ Jl Iring Mulyo Kecamatan Metro Timur Kota Metro \\ ${ }^{1}$ gunayanti2017@gmail.com \\ ${ }^{2}$ pujilabkomegmail.com \\ ${ }^{3}$ Iilikjoko09@gmail.com
}

\begin{abstract}
Abstrak
Kelulusan untuk siswa SMP sudah selesai. Saatnya lulusan SMP mencari sekolah untuk melanjutkan pendidikannya ke jenjang yang lebih tingggi. Sebagian besar banyak siswa lulusan SMP melanjutkan ke SMK dengan tujuan agar ketika lulus sudah mempunyai skill dan bisa membuka peluang usaha ataupun bisa langsung bekerja sesuai dengan jurusan mereka ketika melanjutkan pendidikan ke SMK. Hal yang patut disayangkan adalah kurang terarahnya mereka memilih jurusan yang ada di sekolah kejuruan yang dituju. Situasi semacam ini berdampak pada biaya pendidikan yang sudah terlanjur dikeluarkan. Jadi dengan kata lain baik pada orang tua siswa maupun pemerintah yang mensubsidi sekolah menjadi tidak bermanfaat karena siswa tersebut tidak memiliki kemampuan yang memadai untuk jurusan yang sudah dipilihnya, akibat negatifnya adalah para siswa yang droup out dikarenakan tidak mampu menyelesaikan pendidikan sampai dengan akhir. Berdasarkan iinformasi yang diperoleh dari team penerimaan siswa kejurusan jumlah jurusan yang ada pada SMK Ganesha terdiri dari 4 Jurusan Akuntansi, Administrasi,Teknik Komputer dan Jaringan Teknik Sepeda Motor, penjurusan ditentukan oleh nilai yang disyaratkan pada masing-masing jurusan. Sistem Pendukung Keputusan pemilihan jurusan dengan Metode Analytchical Hierarchy Process. Diharapkan dapat membantu team penerimaan siswa baru dalam menentukan jurusan bagi tiap siswa. Sistem Pendukung Keputusan ini diharapkan membantu sehingga dapat dengan mudah menetukan dimana yang cocok untuk siswa siswi dengan menggunakan nilai yang sudah ada dan dapat diketahui perangkingan dari setiap lokasi, ekmudian data akan diolah untuk menentukan jurusan yang tepat untuk masing-masing siswa yang ada.
\end{abstract}

Kata Kunci : Sistem Pendukung Keputusan, Pengertian Penjurusan SMK, Analytical Hierarchy Process

\section{Pendahuluan}

\subsection{Latar Belakang}

Lembaga Pendidikan setiap tahunnya terus berusaha meningkatkan mutu pendidikan Khususnya Sekolah Menengah Kejuruan (SMK) dengan harapan lulusannya dapat memiliki keterampilan dan keahlian lebih dibandingkan sekolah sederajat, hal tersebut dilakukan demi meningkatkan kualitas lulusan sehingga siap memasuki dunia kerja. Antusias siswa lulusan Sekolah Menengah Pertama (SMP) untuk masuk Sekolah Menengah Kejuruan (SMK) cukup besar, tetapi kebanyakan mereka kurang matang dalam pemilihan Jurusan di SMK tersebut. Akibatnya sukup banyak siswa yang gagal dalam memngikuti pembelajaran sampai selesai atau pada kenaikan kelas pindah jurusan dikarenakan dengan alasan kurang memahami pada jurusan yang diambil ketika awal masuk sekolah. Jelas ini sangat merugikan kedua belah pihak yaitu siswa dan pihak sekolah. Untuk menjadikan pemilihan jurusan pada sekolah menengah kejuruan melakukan penilaian lebih objektif dan sesuai dengan kemampuan siswa siswinya. Dimana sistem tersebut adalah sistem pendukung keputusan.

Sistem pendukung keputusan yang akan dirancang ini menggunakan metode AHP ( analtychical hierarchy process). Pada dasarnya proses pengambilan keputusan adalah memilih suatu alternatif. Peralatan utama AHP adalah sebuah hierarchy fungsional dengan inpututamnya persepsi manusia. Keberadaan hierarchy memungkinkan dipecahkan masalah kompleks atau tidak terstruktur dalam sub sub masalah, lalu ,menyusun menjadi hierarchy. Ahp memiliki banyak keunggulan dalam menjelaskan proses pengambilan keputusan, salah satunya adalah dapat digambarkan secara grafis sehingga mudah dipahami oleh semua pihak yang terlibat dalam pengambilan keputusan.

\subsection{Permasalahan Penlitian}

\subsubsection{Identifikasi Masalah}

Berdasarkan penelitian yang telah dilakukan maka ditemukan beberapa masalah dari penelitian ini yaitu : 
1. Mengganti sistem pengambil keputusan yang ada dalam penerimaan siswa baru untuk menentuka jurusan yang akan dipilih.

2. Proses penyeleksian ini membutuhkan ketelitian dan waktu yang lama karena data siswa akan dibandingkan dengan kriteria dalam penentuan pemilihan jurusan yang ada.

\subsection{Rumusan dan Batasan Masalah}

\subsubsection{Rumusan Masalah}

Rumusan masalah adalah " Bagaimana menetukan Jurusan pada Sekolah Menengah Kejuruan di SMK Ganesha dan menerapkan Metode Analythical Hierarchy Process (AHP) untuk pemilihan jurusan pada Sekolah Menengah Kejuruan SMK Ganesha?

\subsubsection{Batasan Masalah}

Mengingat luasnya cakupan masalah pada identifikasi masalah, maka peneliti memberikan batasan masalah yang akan dianalisa mengingat adanya keterbatasan waktu dalam proses penyusunan yaitu :

1. Perancangan sistem pendukung keputusan ini hanya dirancang untuk pemilihan jurusan akuntansi dan administrasi perakantoran.

2. Kritreria nilai yang digunakan untuk menentukan siswa siswi yang berhak masuk kejurusan akuntansi adalah nilai dari mata pelajaran matematika, bahasa inggris, bahasa indonesia dan ilmu pengetahuan alam.

3. Kriteria nilai yang digunakan untuk menentukan siswa siswi yang berhak masuk kejurusan Administrasi perakantoran adalah nilai mata pelajaran bahasa indonesia, teknologi informasi dan komunikasi, bahasa inggris dan seni.

4. Kriteria pembobotan pada sistem ini menggunaka metode Analythical Hierarchy Process (AHP).

\section{Tinjauan Pustaka}

\subsection{Tinjauan Pustaka}

Tinjauan pustaka pada penelitian ini direferensi sebelumnya yaitu :

\subsubsection{Konsep Dasar Sistem Pendukung}

\section{Keputusan}

Sistem Pendukung Keputusan (SPK) adalah salah satu cara mengorganisir informasi yang dimaksudkan untuk digunakan dalam membuat keputusan. Menurut, "Sistem Pendukung Keputusan merupakan penggabungan sumber sumber kecerdasan individu dengan kemampuan komponen untuk memperbaiki kualitas keputusan. Sistem Pendukung Keputusan juga merupakan sistem informasi berbasis komputer untuk manajemen pengambil keputusan yang menangani masalah - masalah semi terstruktur. a. Penelitian dilakukan oleh Ardian Fawaid dan Anggraini Mulwinda ( 2014) “ Sistem Pendukung Keputusan Penerimaan Peserta Didik Baru Menggunakan Metode Analythical Hierarchy Process /Ahp “ Jurnal Teknik Elektro Vol 6 No.2, Juli 2014. Penelitian ini membahas tentang Sistem Pendukung Keputusan penerimaan calon siswa baru yang memiliki kompetensi agar dapat menunjang mutu dan kualitas sekolahtersebut.

b. Penelitian dilakukan oleh Novia Sulviatin, Moch. Kautsar Shopan, Yeni Kustyaningsih (2014) “ Model Enrollment Penerimaan Siswa Baru Sekolah Menengah Pertama Negeri Menggunakan Metode Ahp \& Saw ", Jurnal Simantec Vol 4 No.2 Desemeber 2014. Penelitian ini membahas tentang Penerimaan siswa baru yang dilakukan secara manual oleh pihak sekolah sehingga menyebabkan proses berlangsung lama. Sehingga dibuatlah Enrollment dimulai dari pendaftaran online sebagai bentuk sistem pendukung keputusan penerimaan siswa baru yang lebih baik kedepannya.

c. Penelitian dilakukan oleh Ayu Wulandari, Rika Yunitarini, Trunojoyo Mandiri (2015) “Perancangan dan Pembuatan Sistem Pendukung Keputusan Penentuan Pemberian Beasiswa Menggunakan Metode Fuzzy Analythical Hierarchy Process (FAHP) dan Oreste", Jurnal Simantec Vol.4 No.3 Juni 2015. Penelitian ini membahas tentang Proses penyeleksian penerima bantuan beasiswa untuk mahasiswa aktif kuliah, dan Sistem Pendukung Keputusan menggunakan Fuzzy Analythical Hierarchy Process digunakan untuk kondisi dimana sekumpulan alternatif akan diurutkan berdasarkan kriteria sesuai dengan tingkat kepentingannya.

\subsection{Landasan Teori}

\subsubsection{Karakteristik Sistem Pendukung Keputusan}

Sistem Pendukung keputusan di rancang secara khusus untuk mendukung seseorang yang harus mengambil keputusan - keputusan tertentu. Menurut (Oetomo, 2002) ada beberapa karakteristik sistem pendukung keputusan yaitu :

1. Interaktif SPK memiliki user interface yang komunikatif sehingga pemakai dapat melakukan akses secara cepat ke data dan memperoleh informasi yang dibutuhkan.

2. Fleksibel SPK memiliki sebanyak mungkin variabel masukkan, kemampuan untuk 
mengolah dan memberikan keluaran yang menyajikan alternatif-alternatif keputusan kepada pemakai.

3. Data kualitas SPK memiliki kemampuan menerima data kualitas yang dikuantitaskan yang sifatnya subyektif dari pemakainya, sebagai data masukkan untuk pengolahan data. Misalnya penilaian terhadap kecantikan yang bersifat kualitas, dapat dikuantitaskan dengan pemberian bobot nilai seperti 75 atau 90.

4. Prosedur pakar SPK mengandung suatu prosedur yang dirancang berdasarkan rumusan formal atau juga beberapa prosedur kepakaran seseorang atau kelompok dalam menyelesaikan suatu bidang masalah dengan fenomena tertentu.

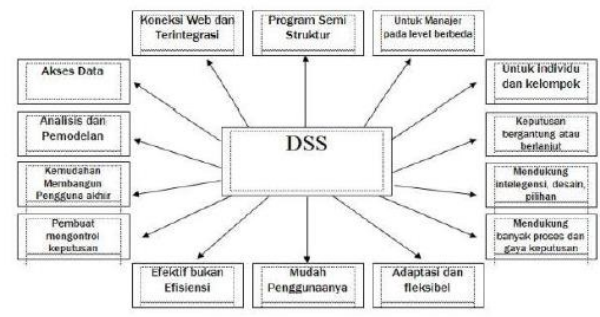

Gambar 1. Karakteristik Sistem Pendukung Keputusan

\subsubsection{Komponen Sistem Pendukung Keputusan} Menurut (Surbakti, 2002) komponen-komponen model konseptual seperti gambar 2 dari SPK adalah sebagai berikut :

1. Data management termasuk database yang mengandung data relevan untuk berbagai situasi dan diatur oleh software yang disebut Database Management System (DBMS).

2. Model management melibatkan model finansial, statistikal, management sience, atau berbagai model kuantitatif lainnya, sehingga dapat memberikan ke sistem suatu kemampuan analisis dan management software yang dibutuhkan.

3. Communication user dapat berkomunikasi dan memberikan perintah Sistem pendukung keputusan melalui sub sistem ini. Ini berarti menyediakan antar muka.

4. Knowledge management sub sistem optional ini dapat mendukung sub sistem lain atau bertindak sebagai komponen yang berdiri sendiri.

Pengertian yang sama, shingga walaupun kriteria pilihan hanya sedikit namun mempunyai makna yang besar terhadap tujuan yang ingin dicapai. Setelah kriteria ditetapkan, selanjutnya adalah

\section{MODEL KONSEPTUAL SPK}

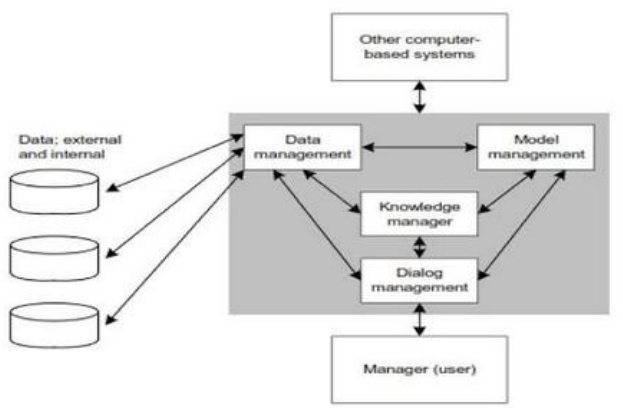

Gambar 2. Model Konseptual Sistem Pendukung Keputusan

\subsubsection{Metode Analythical Hierarchy Process}

Terdapat tiga prinsip utama dalam pemecahan masalah dalam AHP menurut Saaty, yaitu: Decompositiot, Comparative Judgement, dan Logical Concistency. Secara garis besar prosedur AHP meliputi tahapan sebagai berikut:

1) Dekomposisi masalah;

2) Penilaian/pembobotan untuk membandingkan elemen-elemen;

3) Penyusunan matriks dan Uji consistensi;

4) Penetapan prioritas pada masing-masing hirarki;

5) Sistesis dari prioritas; dan

6) Pengambilan/penetapan keputusan. Berikut uraian singkatnya.

\section{Dekomposisis Masalah/Menyusun Hirarki}

Dekomposisi masalah adalah langkah dimana suatu tujuan (Goal) yang telah ditetapkan selanjutnya diuraikan secara sistematis kedalam struktur yang menyusun rangkaian sistem hingga tujuan dapat dicapai secara rasional. Dengan kata lain, sutu tujuan (goal) yang utuh, didekomposisi (dipecahkan) kedalam unsur penyusunnya. Apabila unsur tersebut merupakan kriteria yang dipilih seyogyanya mencakup semua aspek penting terkait dengan tujuan yang ingin dicapai. Namun kita harus tetap mempertimbangkan agar kriteria yang dipulih benar-benar mempunyai makna bagi pengambilan keputusan dan tidak mempunyai makna atau menentukan alternatif atau pilihan penyelesaian masalah. Sehingga apabila digambarkan kedalam bentuk bagan hierarki seperti ditunjukkan pada Gambar 3. 


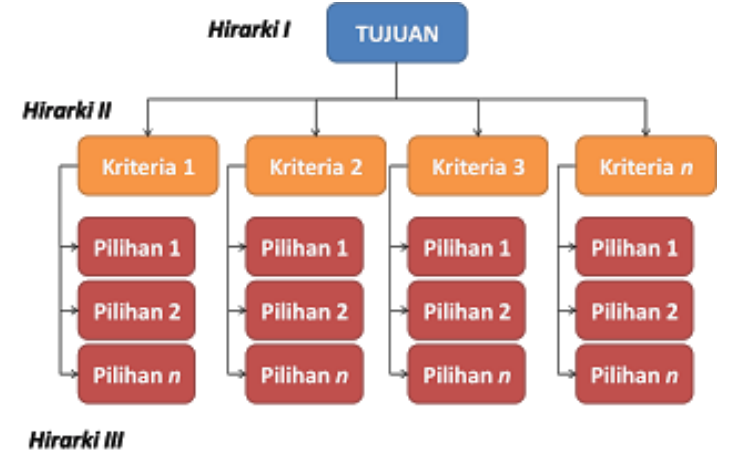

Gambar 3. Hirarki Analythical Hirerachy Process

Hirarki utama (Hirarki I) adalah tujuan/ fokus/ goal yang akan dicapai atau penyelesaian persoalah/ masalah yang dikaji. Hierarki kedua (Hirarki II) adalah kriteria, kriteria apa saja yang harus dipenuhi oleh semua alternatif (penyelesaian) agar layak untuk menjadi pilihan yang paling ideal, dan Hirarki III adalah alternatif aatau pilihan penyelesaian masalah. Ingat...!! Penetapan hierarki adalah sesuatu yang sangat relatif dan sangat bergantung dari persoalan yang dihadapi. Pada kasus-kasus yang lebih kompleks, anda bisa saja menyusun beberapa hirarki (bukan hanya tiga), bergantung pada hasil dekomposisi yang telah anda lakukan, perhatikan contoh hierarki berikut.

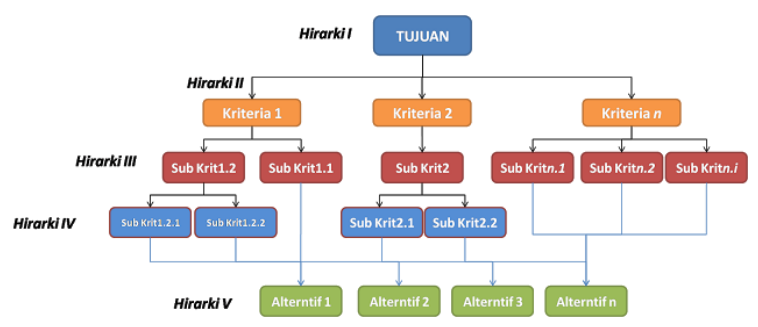

Gambar 4. Hirarki Analythical Hierarchy Process

\section{Penilaian / Pembandingan Elemen}

Apabila proses dekomposisi telah selasai dan hirarki telah tersusun dengan baik. Selanjutnya dilakukan penilaian perbandingan berpasangan (pembobotan) pada tiap-tiap hirarki berdasarkan tingkat kepentingan relatifnya. Pada contoh di atas, maka perbandingan dilakkukan pada Hirarki III (antara alternatif), dan pada Hirarki II (antara kriteria).

Penilaian atau pembobotan pada Hirarki III, dimaksudkan untuk membandingkan nilai atau karakter pilihan berdasarkan tiap kriteria yang ada. Misalnya antara pilihan 1 dan pilihan 2, pada kriteria 1, lebih penting pilihan 1, selanjutnya antara pilihan 1 dan pilihan 3 , lebih penting pilihan 3 dan seterusnya hingga semua pilihan akan dibandingkan satu-persatu (secara berpasangan). Hasil dari penilaian adalah nilai/bobot yang merupakan karakter dari masing - masing alternatif. Penilaian atau pembobotan pada Hierarki II, dimaksudkan untuk membandingkan nilai pada masing-masing kriteria guna mencapai tujuan. Sehingga nantinya akan diperoleh pembobotan tingkat kepentingan masing-masing kriteria untuk mencapai tujuan yang telah ditetapkan. Prosedur penilaian perbandingan berpasangan dalam AHP, mengacu pada skor penilaian yang telah dikembangkan oleh Thomas L Saaty, sebagai berikut:

Tabel 1. Skor Penilaian Kepentingan Analythical Hierarchy Process

\begin{tabular}{|c|l|}
\hline $\begin{array}{c}\text { Intensitas } \\
\text { Pentingnya }\end{array}$ & \multicolumn{1}{c|}{ Defenisi } \\
\hline 1 & Kedua elemen/alternatif sama pentingnya (equal) \\
\hline 3 & Elemen A sedikit lebih esensial dari elemen B (moderate) \\
\hline 5 & Elemen A lebih esensial dari elemen B (strong) \\
\hline 7 & Elemen A jelas lebih esensial dari elemen B (very strong) \\
\hline 9 & Elemen A mutlak lebih esensial dari elemen B (very strong) \\
\hline $2,4,6,8$ & Nilai-nilai antara di antara dua perimbangan yang berdekatan \\
\hline
\end{tabular}

Dalam pembobotan tingkat kepentingan atau penilaian perbandingan berpasangan ini berlaku hukum aksioma reciprocal, artinya apabila suatu elemen A dinilai lebih esensial (5) dibandingkan dengan elemen B, maka B lebih esensial 1/5 dibandingakan dengan elemen A. Apabila elemen A sama pentingnya dengan B maka masing-masing bernilai $=1$.

Dalam pengambilan data, misalnya dengan menggunakan kuisioner, prosedur perbandingan berganda dapat dilakukan dengan menggunakan kuisioner berupa matriks atau semantik difrensial.

\section{Metodologi Penelitian}

Pada tahap ini pengumpulan data yang dilakukan menggunakan metode pengumpulan data berikut ini :

a. Pengamatan (observasi)

Teknik ini dilakukan dengan cara mengamati langsung terhadap objek penelitian yaitu siswa siswi lulusan smp yang akan mendaftar di SMK.

b. Wawancara (interview)

Metode wawancara dilakukan dengan cara melakukan tanya jawab secara langsung kepada bagian-bagian terkait yang terlibat dalam proses penerima siswa baru untuk penjurusan di SMK Ganesha tersebut.

c. Studi Pustaka (Library Research) 
Metode penelitian ini dilakukan dengan cara mengambil teori - teori buku - buku dan literatur - literatur yang ada pada perpustakaan, internet, akademi atau tempat lain yang berhubungan langsung maupun yang tidak langsung terhadap pokok pembahasan tentang data calon siswa siswa penjurusan di SMK tersebut.

d. Dokumentasi

Metode penelitian dokumentasi ini dilakukan dengan mengumpulkan beberapa berkas dari data calon siswa siswa penjurusan di SMK tersebut.

\section{Pembahasan}

Langkah - langkah yang harus dilakukan untuk menentukan jurusan adalah sebagai berikut :

1. Membuat matriks perbandingan berpasangan pada tahap ini dilakukan penilaian perbandingan antara satu kriteria dengan kriteria lain. Hasil penilaian bisa dilihat dalam tabel 2

Tabel 2. Matriks Perbandingan Berpasangan

\begin{tabular}{|l|l|l|l|l|}
\hline & Matematika & $\begin{array}{l}\text { Bahasa } \\
\text { Inggris }\end{array}$ & $\begin{array}{l}\text { Bahasa } \\
\text { Indonesia }\end{array}$ & TIK \\
\hline Matematika & 1 & 3 & 5 & 7 \\
\hline $\begin{array}{l}\text { Bahasa } \\
\text { Inggris }\end{array}$ & 0.33 & 1 & 3 & 5 \\
\hline $\begin{array}{l}\text { Bahasa } \\
\text { Indonesia }\end{array}$ & 0.2 & 0.33 & 1 & 3 \\
\hline TIK & 0.14 & 0.2 & 0.33 & 1 \\
\hline Jumlah & 1.67 & 5.53 & 9.33 & 16 \\
\hline
\end{tabular}

Angka 1 pada kolom matematika baris matematika menggambarkan tingkat kepentingan yang sama antara matematika dengan matematika dengan matematika, sedangkan angka 3 pada kolom b.inggris baris matematika menunjukkan bahasa indonesia sedikit lebih penting di bandingkan dengan matematika.angka 0,33 pada kolom matematika merupakan hasil perhitungan 1/nilai pada kolom bahasa indonesia.Angka-angka yang lain diperoleh dengan cara yang sama.

2. Membuat matriks nilai kriteria

3. Matriks baris kolom baru = nilai baris kolom lama/jumlah masing-masing kolom lama. Hasil perhitungan bisa dilihat dalama tabel 3 .

Tabel 3. Matriks Penilain Kriteria

\begin{tabular}{|l|l|l|l|l|l|l|}
\hline & $\mathrm{Mm}$ & B.Ing & B.I & TIK & Jumlah & Prioritas \\
\hline Mm & $\begin{array}{l}0.6 \\
0\end{array}$ & 0.66 & 0.54 & 0.43 & 2.23 & 0.56 \\
\hline B Ing & $\begin{array}{l}0.2 \\
0\end{array}$ & 0.22 & 0.32 & 0.31 & 1.06 & 0.26 \\
\hline B.I & $\begin{array}{l}0.1 \\
2\end{array}$ & 0.07 & 0.12 & 0.19 & 0.5 & 0.12 \\
\hline TIK & $\begin{array}{l}0.0 \\
8\end{array}$ & 0.04 & 0.04 & 0.06 & 0.22 & 0.06 \\
\hline
\end{tabular}

Untuk baris pertama nilai 0.23 merupakan hasil penjumlahan dari $0.60+0.66+0.54+0.43$. Nilai pada kolom prioritas diperoleh dari nilai pada kolom jumlah dibagi dengan jumlah kriteria, dala hal ini 4.

4. Membuat Matriks penjumlahan setiap baris Matriks ini dibuat dengan mengalikan nilai prioritas dengan matriks perbandingan berpasangan.

Tabel 4. Matriks Penjumlahan Setiap Baris

\begin{tabular}{|l|l|l|l|l|l|}
\hline & $\mathrm{Mm}$ & B.Ing & B.I & TIK & Jumlah \\
\hline $\mathrm{Mm}$ & 0.56 & 0.79 & 0.60 & 0.42 & 2.36 \\
\hline B.Ing & 0.18 & 0.26 & 0.36 & 0.30 & 1.10 \\
\hline B.I & 0.11 & 0.09 & 0.12 & 0.18 & 0.50 \\
\hline TIK & 0.09 & 0.05 & 0.04 & 0.06 & 0.24 \\
\hline
\end{tabular}

Kolom jumlah pada tabel 4 diperoleh dengan menjumlahkan nilai pada masing -masing baris di tabel tersebut.

5. Perhitungan rasio konsistensi

6. Perhitungan ini digunakan untuk memastikan bahwa nilai rasio konsistensi $(\mathrm{CR})>0.1$ Jika ternyata nilai $\mathrm{CR}$ lebih besar dari 0.1 maka matriks perbandingan berpasangan harus di perbaiki.

Tabel 5. Perhitungan Rasio Konsistensi

\begin{tabular}{|l|l|l|l|}
\hline & $\begin{array}{l}\text { Jumlah } \\
\text { Perbaris }\end{array}$ & Prioritas & Hasil \\
\hline $\mathrm{Mm}$ & 2.36 & 0.56 & 2.92 \\
\hline B.Ing & 1.10 & 0.26 & 1.36 \\
\hline B .I & 0.50 & 0.12 & 0.62 \\
\hline TIK & 0.24 & 0.06 & 0.30 \\
\hline
\end{tabular}

Kolom jumlah perbaris diperoleh dari kolom jumlah, sedangkan kolom prioritas diperoleh dari kolom prioritas. Dengan ketentuan sebagai berikut :

Jumlah (jumlahan dari nilai-nilai hasil) : 5.20

N(jumlah kriteria): 4

Maks (jumlah-n)/n):1.30-4)/4=-0.67

$\mathrm{CR}(\mathrm{CI} / \mathrm{IR})=-0.75$

Oleh karena $\mathrm{CR}<0.1$ maka rasio konsistensi dari perhitungan tersebut bisa diterima.

Menentukan prioritas subkriteria perhitungan sub kriteria dilakukan terhadap sub sub dari semua kriteria.

a. Menghitung Matriks Perbandingan Berpasangan Matematika 
Tabel 6. Matriks Perbandingan Berpasangan Kriteria Matematika

\begin{tabular}{|l|l|l|l|}
\hline & Baik & Cukup & Kurang \\
\hline Baik & 1 & 3 & 5 \\
\hline Cukup & 0.33 & 1 & 3 \\
\hline Kurang & 0.2 & 0.33 & 1 \\
\hline & 1.53 & 4.33 & 9 \\
\hline
\end{tabular}

Tabel 7. Matriks Kriteria Matematika

\begin{tabular}{|l|l|l|l|l|l|l|}
\hline & $\begin{array}{l}\text { Ba } \\
\text { ik }\end{array}$ & $\begin{array}{l}\text { Cuk } \\
\text { up }\end{array}$ & $\begin{array}{l}\text { Kur } \\
\text { ang }\end{array}$ & $\begin{array}{l}\text { Jum } \\
\text { lah }\end{array}$ & $\begin{array}{l}\text { Prior } \\
\text { itas }\end{array}$ & $\begin{array}{l}\text { Prior } \\
\text { itas } \\
\text { Sub }\end{array}$ \\
\hline Baik & $\begin{array}{l}0.6 \\
5\end{array}$ & 0.69 & 0.56 & 1.90 & 0.63 & 1 \\
\hline $\begin{array}{l}\text { Cuk } \\
\text { up }\end{array}$ & $\begin{array}{l}0.2 \\
2\end{array}$ & 0.23 & 0.33 & 0.78 & 0.26 & 0.41 \\
\hline $\begin{array}{l}\text { Kur } \\
\text { ang }\end{array}$ & $\begin{array}{l}0.1 \\
3\end{array}$ & 0.08 & 0.11 & 0.32 & 0.11 & 0.17 \\
\hline
\end{tabular}

Tabel 8. Matriks Penjumlahan Setiap baris Kriteria Matematika

\begin{tabular}{|l|l|l|l|l|}
\hline & Baik & Cukup & Kurang & Jumlah \\
\hline Baik & 0.63 & 0.78 & 0.55 & 1.96 \\
\hline Cukup & 0.21 & 0.26 & 0.33 & 0.80 \\
\hline Kurang & 0.13 & 0.09 & 0.11 & 0.33 \\
\hline
\end{tabular}

Tabel 9. Perhitungan Rasio Konsistensi Kriteria Matematika

\begin{tabular}{|l|l|l|l|}
\hline & $\begin{array}{l}\text { Jumlah } \\
\text { Per Baris }\end{array}$ & Prioritas & Hasil \\
\hline Baik & 1.96 & 0.63 & 2.59 \\
\hline Cukup & 0.80 & 0.26 & 1.06 \\
\hline Kurang & 0.33 & 0.11 & 0.44 \\
\hline & & & 4.09 \\
\hline
\end{tabular}

b. Menghitung matriks perbandingan berpasangan B.Inggris

Tabel 10. Matriks Perbandingan Berpasangan Kriteria B.Inggris

\begin{tabular}{|l|l|l|l|}
\hline & Baik & Cukup & Kurang \\
\hline Baik & 1 & 2 & 6 \\
\hline Cukup & 0.5 & 1 & 2 \\
\hline Kurang & 0.17 & 0.5 & 1 \\
\hline Jumlah & 1.67 & 3.50 & 9 \\
\hline
\end{tabular}

Tabel 11. Matriks Nilai Kritria B.Inggris

\begin{tabular}{|l|l|l|l|l|l|l|}
\hline & Baik & Cukup & Kurang & Jumlah & Prioritas & $\begin{array}{l}\text { Sub } \\
\text { Prioritas }\end{array}$ \\
\hline Baik & 0.60 & 0.57 & 0.67 & 1.84 & 0.61 & 1 \\
\hline Cukup & 0.30 & 0.29 & 0.22 & 0.81 & 0.27 & 0.44 \\
\hline Kurang & 0.10 & 0.14 & 0.11 & 0.35 & 0.12 & 0.19 \\
\hline
\end{tabular}

Tabel 12. Matriks Penjumlahan Setiap Baris Kriteria B.Inggris

\begin{tabular}{|l|l|l|l|l|}
\hline & Baik & Cukup & Kurang & Jumlah \\
\hline Baik & 0.61 & 0.54 & 0.72 & 1.87 \\
\hline Cukup & 0.31 & 0.27 & 0.24 & 0.82 \\
\hline Kurang & 0.10 & 0.14 & 0.12 & 0.36 \\
\hline
\end{tabular}

Tabel 13. Perhitungan Rasio Konsistensi Kriteria B.Inggris

\begin{tabular}{|l|l|l|l|}
\hline & $\begin{array}{l}\text { Jumlah Per } \\
\text { baris }\end{array}$ & Prioritas & Hasil \\
\hline Baik & 1.87 & 0.61 & 2.78 \\
\hline Cukup & 0.81 & 0.27 & 1.09 \\
\hline Kurang & 0.36 & 0.12 & 0.48 \\
\hline
\end{tabular}

c. Menghitung Perbandingan Berpasangan Kriteria B.Indonesia

\begin{tabular}{|l|l|l|l|}
\hline & Baik & Cukup & Kurang \\
\hline Baik & 1 & 3 & 4 \\
\hline Cukup & 0.33 & 1 & 3 \\
\hline Kurang & 0.25 & 0.33 & 1 \\
\hline Jumlah & 1.58 & 4.33 & 8 \\
\hline
\end{tabular}

Tabel 14. Matriks Nilai Kriteria B.indonesia

\begin{tabular}{|l|l|l|l|l|l|l|}
\hline & Baik & Cukup & Kurang & Jumlah & Prioritas & $\begin{array}{l}\text { Prioritas } \\
\text { Sub }\end{array}$ \\
\hline Baik & 0.67 & 0.69 & 0.50 & 1.82 & 0.61 & 1 \\
\hline Cukup & 0.21 & 0.23 & 0.38 & 0.82 & 0.27 & 0.45 \\
\hline Kurang & 0.16 & 0.08 & 0.13 & 0.37 & 0.12 & 0.20 \\
\hline
\end{tabular}

Tabel 15. Matriks Penjumlahan Setiap Baris kriteria B.indonesia

\begin{tabular}{|l|l|l|l|l|}
\hline & Baik & Cukup & Kurang & Jumlah \\
\hline Baik & 0.61 & 0.81 & 0.48 & 1.90 \\
\hline Cukup & 0.20 & 0.27 & 0.36 & 0.83 \\
\hline Kurang & 0.15 & 0.60 & 0.12 & 0.87 \\
\hline
\end{tabular}

Tabel 16. Perhitungan Rasio Konsistensi Kriteria B.Indonesia

\begin{tabular}{|l|l|l|l|}
\hline & $\begin{array}{l}\text { Jumlah } \\
\text { Perbaris }\end{array}$ & Prioritas & Hasil \\
\hline Baik & 1.90 & 0.61 & 2.51 \\
\hline Cukup & 0.83 & 0.27 & 1.10 \\
\hline Kurang & 0.87 & 0.12 & 0.99 \\
\hline
\end{tabular}

Menghitung matriks perbandingan berpasangan TIK 
Tabel 17. Matriks Perbandingan berpasangan Kriteria TIK

\begin{tabular}{|l|l|l|l|}
\hline & Baik & Cukup & Kurang \\
\hline Baik & 1 & 2 & 5 \\
\hline Cukup & 0.5 & 1 & 4 \\
\hline Kurang & 0.2 & 0.25 & 1 \\
\hline Jumlah & 1.7 & 3.25 & 10 \\
\hline
\end{tabular}

Tabel 18 Matriks Nilai Kriteria TIK

\begin{tabular}{|l|l|l|l|l|l|l|}
\hline & Baik & Cukup & Kurang & Jumlah & Prioritas & $\begin{array}{l}\text { Sub } \\
\text { prioritas }\end{array}$ \\
\hline Baik & 0.59 & 0.62 & 0.50 & 1.71 & 0.57 & 1 \\
\hline Cukup & 0.29 & 0.31 & 0.40 & 1.00 & 0.33 & 0.59 \\
\hline Kurang & 0.12 & 0.08 & 0.10 & 0.30 & 0.10 & 0.17 \\
\hline
\end{tabular}

Tabel 19. Matriks Penjumlahan Setiap Baris Kriteria TIK

\begin{tabular}{|l|l|l|l|l|}
\hline & Baik & Cukup & Kurang & Jumlah \\
\hline Baik & 0.57 & 0.66 & 0.50 & 1.73 \\
\hline Cukup & 0.28 & 0.33 & 0.40 & 1.01 \\
\hline Kurang & 0.11 & 0.08 & 0.10 & 0.29 \\
\hline
\end{tabular}

Tabel 20. Perhitungan Rasio Konsistensi Kriteria TIK

\begin{tabular}{|l|l|l|l|}
\hline & $\begin{array}{l}\text { Jumlah } \\
\text { Per Baris }\end{array}$ & Prioritas & Hasil \\
\hline Baik & 1.73 & 0.57 & 2.30 \\
\hline Cukup & 1.01 & 0.33 & 1.39 \\
\hline Kurang & 0.29 & 0.10 & 0.39 \\
\hline
\end{tabular}

Tabel 21. Matriks Hasil

\begin{tabular}{|l|l|l|l|}
\hline Matematika & B.Inggris & B.Indo & TIK \\
\hline 0.56 & 0.26 & 0.12 & 0.06 \\
\hline Baik & Baik & Baik & Baik \\
\hline 1 & 1 & 1 & 1 \\
\hline Cukup & Cukup & Cukup & Cukup \\
\hline 0.41 & 0.44 & 0.45 & 0.59 \\
\hline Kurang & Kurang & Kurang & Kurang \\
\hline 0.17 & 0.19 & 0.20 & 0.17 \\
\hline
\end{tabular}

Tabel 22. Nilai Siswa Siswi

\begin{tabular}{|l|l|l|l|l|}
\hline & Matematika & B.Inggris & B.I & TIK \\
\hline A & Cukup & Cukup & Baik & Baik \\
\hline B & Baik & Kurang & Cukup & Cukup \\
\hline C & Cukup & Baik & Baik & Baik \\
\hline
\end{tabular}

Tabel 23. Nilai Akhir

\begin{tabular}{|l|l|l|l|l|l|}
\hline & Matematika & B.Inggris & B.I & TIK & Total \\
\hline A & 0.23 & 0.11 & 0.12 & 0.06 & 0.52 \\
\hline B & 0.56 & 0.05 & 0.05 & 0.03 & 0.69 \\
\hline C & 0.23 & 0.26 & 0.12 & 0.06 & 0.67 \\
\hline
\end{tabular}

Nilai 0.23 pada kolom matematika baris $\mathrm{A}$ diperoleh dari nilai murid A untuk matematika, yaitu cukup dengan prioritas 0.41 dikalikan

dengan prioritas matematika sebesar 0.56. Kolom total diperoleh dari penjumlahan masing-masing barisnya. Nilai Total adalah yang dipakai sebagai dasar untuk merangking nilai siswa siswi dalam penentuan jurusan yang diambil. Semakin besar nilainya, maka siswa siswi tersebut akan semakin menjadi yang terbaik, dan untuk pembobotan nilai siswa siswi ke dalam matriks hasil maka perbandinganya adalah :

1. Nilai sembilan puluh sampai seratus kriterianya baik.

2. Nilai tujuh puluh sampai delapan puluh kriterianya cukup.

3. Nilai lima puluh sampai enam puluh kriterianya kurang.

\section{Kesimpulan}

Berdasarkan uraian pembahasan dari penelitian yang telah dilakukan, maka dapat diperoleh kesimpulan sebagai berikut :

1. Sistem pendukung keputusam yang sudah ada dapat memopermudah panitia penentuan jurusan di SMK Ganesha Lampung Timur untuk mempercepat proses pemilihan siswa siswi dengan cara menginput nilai nilai dan langsung mendapatkan hasilnya, dibandingkan dengan sebelumnya penentuan jurusan masih dengan cara manual dengan cara memberi pilihan pada siswa tanpa melihat kemampuan akademiknya.

2. Perancangan metode Analythical Hierarchy Process (AHP) untuk penentuan jurusan bagi siswa siswi dapat diterapkan dengan sangat baik dalam pengimplementasiannya, AHP mampu menunjukkan bahwa satu alternatif merupakan prioritas keputusan.

\section{Daftar Pustaka}

Ayu Wulandari, R. Y. (2015). Perancangan dan Pembuatan Sistem Pendukung Keputusan Penentuan Pemberian Beasiswa Menggunakan Metode Fuzzy Analythical Hierarchy Process (FAHP) dan Oreste. Jurnal Simantec Vol.4 No.3 Juni.

Keen, P. a. (2006). Decision Support System and Organizational Perspective. Reading $\mathrm{Ma}$ : Addison -Wesley.

Mulwinda, A. f. (2014). (2014). “ Sistem Pendukung Keputusan Penerimaan Peserta Didik Baru Menggunakan Metode 
Analythical Hierarchy Process. Jurnal Teknik Electro Vol.6 No.2 Juli.

Novia Sulviatin, M. K. (2014). Model Enrollment Penerimaan Siswa Baru Sekolah Menengah Pertama Negeri Menggunakan M etode Ahp dan Saw (Studi Kasus : Dinas Pendidikan Kab.bangkalan. Jurnal Simantec Vol.4 No.2 Desember.
Oetomo. (2002). Perencanaan dan Pembangunan Sistem Pendukung Keputusan. Yogyakarta: Penerbit Andi Offset.

Oetomo, B. S. (2002). e-Education. Konsep, Teknologi dan Aplikasi Internet Pendidikan . Yogyakarta: Andi Offset .

Surbakti. (2002). Sistem Pendukung Keputusan (Decision Support System), Surabaya. Penerbit PT Gramedia Putra Sarana: Surabaya. 